\title{
The treatment of chronic cough by osteopathy: a case study of a patient with refractory gastroesophageal reflux disease
}

\begin{abstract}
The Gastroesophageal Reflux Disease (GERD) is the most common organic disorder of the digestive tract, resulting from retrograde flow of the gastroduodenal contents into the esophagus and/or organs adjacent to it. GERD has a significant socioeconomic impact and affects the patient's quality of life. Studies have identified that one of the most common clinical manifestations of GERD is chronic cough (CC). Research has been conducted to propose complementary treatments for GERD, such as osteopathy, but have not yet been carried out to assess the osteopathic treatment in patients with chronic cough. Using a case study, the objective was to investigate the effect of osteopathic treatment on chronic cough, the patients' quality of life and the perception of their symptoms in a patient refractory to treatment for atypical GERD. Treatment was done with an hour weekly session, totaling 14 hours, with the application of two questionnaires before and after the end of the consultations: HBQOL (Heartburn Specific Quality of Life Instrument) and the SQGERD (Symptom Questionnaire of Gastroesophageal reflux disease). The results show significant improvement in most analyses of fields, indicating improvement in CC, in other symptoms of GERD and in negative interference of the disorder in the participant's quality of life. Considering the literature on the subject, it is possible to infer that the positive effects of osteopathic manipulation may be related to its action or effects on the anatomical and functional structures and mechanisms related to GERD and CC. In addition, some myofascial anatomical and functional relationships between the esophagus and some body parts justify the treatment of $\mathrm{CC}$ based on osteopathic treatment. We conclude that osteopathy is a promising therapeutic method in the adjuvant treatment of refractory GERD. Given the limitations of the study, they suggest future research that can enhance the quality of osteopathic therapy in cases of CC.
\end{abstract}

Keywords: chronic cough, osteopathy, gastroesophageal reflux, quality of life
Volume 6 Issue 6 - 2017

\author{
Laís Cristina Almeida,' Regina Lúcia Braga \\ Silva Barros,' Krishna de Almeida e Silva,' \\ Vera Lúcia Ângelo Andrade² \\ 'Escola Brasileira de Osteopatia, Brazil \\ ${ }^{2}$ Serviço Diagnóstico em Gastroenterologia SEDIG, Brazil
}

Correspondence: Vera Lúcia Ângelo Andrade, Rua Ceara 1333/201, Belo Horizonte, Minas Gerais, Brazil, Email vera_angelo@hotmail.com

Received: May 19,2017| Published: June 16, 2017
Abbreviations: GERD, gastroesophageal reflux disease; HBQOL, heartburn specific quality of life instrument; SQ-GERD, symptom questionnaire of gastroesophageal reflux disease

\section{Introduction}

Gastroesophageal reflux disease (GERD) occurs when acid or other stomach contents back up in the esophagus. The most common symptom of GERD is heartburn, which, while rarely life-threatening, can greatly reduce a patient's quality of life by affecting daily activities, sleep and what they can eat. ${ }^{1,2}$ A systematic review found the prevalence of GERD to be $10-20 \%$ of the Western world with a lower prevalence in Asia. ${ }^{3,4}$ Typically, the diagnosis of GERD is based on heartburn and acid regurgitation; however, research findings suggest that extraesophageal signs and symptoms are frequent in clinical practice. Clinically troublesome heartburn is seen in about 6\% of the population. Chronic cough, asthma, chronic laryngitis, other airway symptoms and so-called extraesophageal symptoms are called atypical reflux. Studies have identified that one of the common clinical manifestations of atypical GERD is chronic cough. ${ }^{5}$ There are reports of refractoriness when, in the treatment of GERD, the patient remains symptomatic even when using medication and this is very common in atypical GERD. ${ }^{4}$ In some cases the treatment of this disease has a high cost and the patient may present side effects due to the treatment. ${ }^{4-6}$

Research has been carried out to propose complementary treatments to GERD, such as osteopathy. Osteopathy is a therapeutic system used in the correction of musculoskeletal, visceral, fascial and cranial dysfunctions. ${ }^{7,8}$ In 2014, our group published a prospective study confirming the effectiveness of osteopathy as a therapeutic option in the treatment of typical GERD. ${ }^{9}$ Studies have shown a close relationship between transient relaxation of the lower esophageal sphincter and the spatial separation between the diaphragm muscle, when in the presence of GERD. Studies of osteopathy have already shown a relationship between the anatomo-physiology of the esophagus-cardio-tuberosity region and GERD. There are few studies in the medical literature that evaluated the effect of osteopathic treatment in patients with GERD. One of them showed results indicating that osteopathic treatment is efficient for people with GERD refractory to drug treatment. ${ }^{10}$ However, no research has been conducted to evaluate the efficacy of osteopathic treatment in patients with chronic cough with GERD, refractory to the clinical treatment. These are the objectives of the present study.

\section{Case presentation}

A 61-year-old male patient, a dentist from Belo Horizonte, refers to chronic cough since 1999, having already undergone extensive propaedeutic for reflux. He started with a daily dry cough, worsening of symptoms in the supine position and during labor exposure to acrylic. He carried out extensive propaedeutic tests which included $\mathrm{X}$-Ray and tomography of thorax, upper digestive endoscopy, 24-h $\mathrm{pH}$-metry off proton pump inhibitor. The $\mathrm{pH}$ - metry did not show pathological reflux, but the index of symptoms was $73 \%$. 
In the year 2000 we decided to do a therapeutic test using Rabeprazole for six months, with significant improvement. There was a recurrence of symptoms after discontinuation of medication. He made irregular use of Pantoprazole and Seretide, with partial remission of symptoms until May 2001 when he was clinically reevaluated. In 2005 he was re-evaluated clinically, radiologically and laboratorially and no alterations were detected. . At the beginning of 2006 he presented worsening cough and pneumonia was detected. Azithromycin, meticortem and pantoprazole double dose were prescribed. There was clinical improvement, but residual nocturnal cough persisted. In 2007, as the cough didn't subside, even with the therapy, he was submitted to 24-h pH-metry and multichannel intraluminal impedance monitoring, still taking Pantoprazole 40mg twice a day. The examination showed non-acid reflux. A fundoplication was indicated, but the patient refused this therapeutic option. He intermittently used Pantoprazole and Seretide with annual clinical follow-up until 2013. At that year, upper gastrointestinal endoscopy showed grade I esophagitis and videolaryngoscopy showed indirect signs of reflux with mild edema of the arytenoid region. Spirometry did not show pathological alterations.

In March 2014 he was invited to participate in the present research, with osteopathic treatment oriented to GERD. These visits occurred once a week (60 minutes), making 14 consecutive sessions. The Figures $1 \& 2$ show osteopathic care. The HBQOL (Heartburn Specific Quality of Life Instrument) and QS-GERD (Symptom Questionnaire of Gastroesophageal reflux disease) questionnaires were answered before and after treatment. The patient keeps biweekly appointments until today and intermittent use of pantoprazole with episodes of improvement and recrudescence of cough. He reports improvement in his quality of life with the osteopathic treatment.

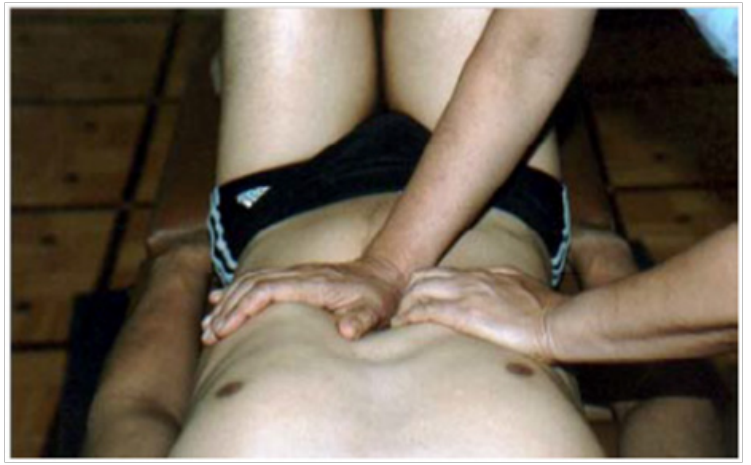

Figure I Example of osteopathic maneuver for the esophagus- cardiotuberosity region.

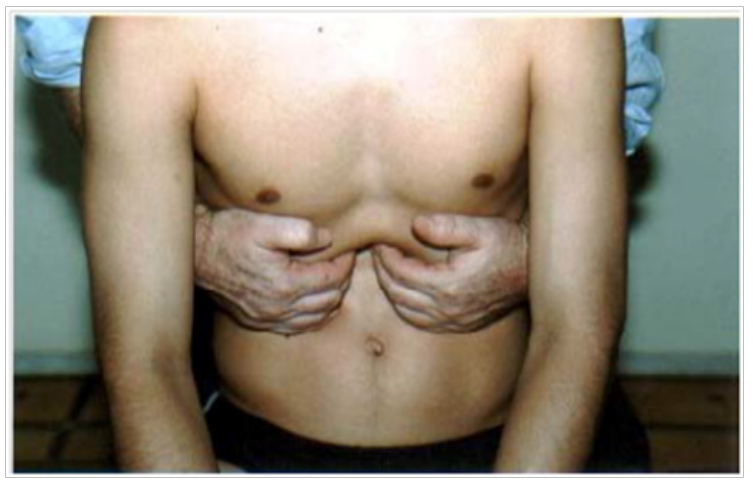

Figure 2 Example of osteopathic maneuver for the esophagus-cardiotuberosity region.

\section{Discussion}

The etiology of atypical GERD with chronic cough is considered Multifactorial. ${ }^{11,12}$ Clinical treatment in general may present many recurrences as in the present case. Therapeutic arsenal is limited including proton pump inhibitors. ${ }^{13,14}$ Osteopathy therefore appears with adjuvant in the treatment of atypical GERD. ${ }^{15}$

Two mechanisms have been proposed to explain the association between GERD and chronic cough: that refluxed gastric contents can reach the upper and lower respiratory tract causing cough; And that reflux of gastric acid content may stimulate vagal nerve terminals present in the esophagus, triggering reflex cough. ${ }^{16,17}$ Uncontrolled studies have demonstrated the association between dysfunction in esophageal motility and the presence of chronic cough. ${ }^{16-18}$ There is also a suggestion of a close relationship between the transient relaxation of the lower esophageal sphincter and the spatial separation between the diaphragm muscle in the presence of GERD. ${ }^{19-21}$ These relationships create hypothesis that would justify the treatment of chronic cough based on the osteopathic maneuvers used.

Studies have already shown improvement in the symptoms of GERD and have shown that the benefit of osteopathy in reducing symptoms is in part due to the relation of its maneuvers to the physiology of this condition. ${ }^{9,22}$ The osteopathic treatment of GERD aims at the normalization of dysfunctions of structures related to the esophagus-cardio-tuberosity region, by means of soft stretches, manipulations and passive mobilizations. ${ }^{23-25}$

The transitory relaxation is a physiologic mechanism in response to the gastric strain via vagal reflex. In individuals with GERD the sphincter opening seems to be bigger, favoring the pathological reflux and the spatial separation between the diaphragm muscle and the inferior sphincter of the esophagus. Another study related to chronic cough also suggests that a tracheal reflex esophagus bronchial triggered by the vagal nerve by acid reflux to the inferior esophagus and its aspiration is considered as being the GERD mechanism. ${ }^{23-25}$

The esophagus is followed by the vagus nerve, forming the esophageal plexus and the vagal trunks as well as the pneumogastric nerves. Studies have shown that dysfunctions in this region may be followed by disorders related to the vagus nerve and also to the tonus and elasticity of the diaphragm pillars, which forms the fibrous annulus of the esophageal orifice. ${ }^{25}$

The diaphragmatic part of the esophagus is related to the diaphragm pillars, to the left triangular ligament of the liver, to the parietal peritoneum that recovers the diaphragm and esophageal peritoneum. Through the diaphragm, it is also related to the costal cartilages, 5th, 6th, 7th and 9th ribs. The diaphragm is also connected to the thick tuberosity of the stomach by the gastrophrenic ligament, whereas the inferior orifice of the esophagus has fibrous insertions with the pleura and the mediastinum. ${ }^{27,28}$

The mobility of the peritoneum ensures the relation of mobility of the organs in the peritoneal cavity as well as the close connection of the esophagus with the cervical fascia, since the esophagus is located between the conjunctive space of the superficial and deep lamina of the cervical fascia. Being the esophagus the continuation of the pharynx, which is a suspended tube on the cranial base by the pharyngobasilar fascia, such data make suppose that the relations between the sphincter of the esophagus, the cervical and the cranial base also establish a possible connection, which would help in the positive effects of osteopathic manipulations on chronic cough. 
The arguments presented could explain the patient's improvement through osteopathic maneuvers. There would be modifications in the mechanisms that relate the GERD with chronic cough brought about by the treatments above mentioned, since the manipulations provide some specific modifications (1) in the mechanisms that regulate refluxed gastric contents which reach the upper and lower respiratory tract causing cough and/or (2) in mechanisms of reflux of acid gastric content, discouraging the vagal nerve endings present in the esophagus, helping in the reduction of reflex cough and/or (3) influence in the dysfunction mechanisms in esophageal motility that may induce the presence of chronic cough. . $4,25,27^{2}$

The therapeutic relation between osteopathy and typical GERD is clearly established in literature, and our group published one of the prospective papers. ${ }^{9}$ The importance of this report is the one that shows the therapeutic effectiveness in atypical GERD, having cough as a clinical manifestation. It is concluded that osteopathy is a promising therapeutic method in the adjuvant treatment of atypical refractory GERD. Given the limits of this study, we suggest future research to validate the quality of osteopathy therapy in cases of chronic cough.

\section{Acknowledgments}

None.

\section{Conflicts of interest}

Authors declare that there is no conflict of interest.

\section{References}

1. Dent J, El-Serag HB, Wallander MA, et al. Epidemiology of gastro-oesophageal reflux disease: a systematic review. Gut. 2005;54(5):710-717.

2. Moraes-Filho JPP, Chinzon D, Eisig JN, et al. Prevalence of heartburn and gastroesophageal reflux disease in the urban Brazilian population. Arq Gastroenterol. 2005;42(2):122-127.

3. Kahrilas PJ, Talley NJ, Bonis PAL. Clinical manifestations and diagnosis of gastroesophageal reflux in adults. Up To Date; 2007.

4. Roman S, Gyawali CP, Savarino E, et al. Ambulatory reflux monitoring for diagnosis of gastro-esophageal reflux disease: Update of the Porto consensus and recommendations from an international consensus group. Neurogastroenterol Motil. 2017.

5. Irwin RS, Richter JE. Gastroesophageal reflux and chronic cough. Am J Gastroenterol. 2000;95(8):S9-S14.

6. Katz PO, Gerson LB, Vela MF. Guidelines for the diagnosis and management of gastroesophageal reflux disease. Am J Gastroenterol. 2013;108(3):308-328.

7. Staubesand J, Li Y. Begriff und Substrat der Faziensklerose bei chronisch-venöser Insuffizienz. Phlebologie. 1997;26:72-79.

8. Schleip R. Passive muscle stiffness may be influenced by active contractility of intramuscular connective tissue. Medical Hypotheses. 2006;66:66-71.

9. Almeida LC, Barros RLBS, Silva KA, et al. Osteopathic treatment effectiveness in quality of life and perception of patients with symptoms of reflux disease refractory to gastroesophageal treatment drug. GED Gastroenterol Endosc Dig. 2015;34(1):10-17.
10. Gemelli M, Ulbricht L, Romaneli E. Evaluation of Gastroesophageal Reflux in Infants Treated with Osteopathy Using the I-GERQ-R Questionnaire. XIII Mediterranean Conference on Medical and Biological Engineering and Computing; 2013. 1037-1070 p.

11. Gastroenterologia FBD, Digestiva SBDE, Digestiva CBDC, et al. Doença do refluxo gastroesofágico: diagnóstico. Rev Assoc Med Bras. 2011;57(5):499-507.

12. Barbuti RC, Moraes-Filho JP. Doença do refluxo gastroesofágico; Gastroesophageal disease. Rev Bras Med. 2010;67(12).

13. Escobar AG, Zanin I, Mattos AAd, et al. Correlaçäo entre hipotonia de esfíncter esofágico inferior e doença do refluxo gastroesofágico. GED gastroenterol endosc dig. 2001;20(1):21-24.

14. Abrahão LJ Jr, Lemme EM, Carvalho BB, et al. Relationship between the size of hiatal hernia and esophageal acid exposure time in erosive and non-erosive reflux disease. Arq Gastroenterol. 2006;43(1):37-40.

15. Jarosz R, Zimmerman TG, Van Arsdale D. Clinical management of gastroesophageal reflux disease. Osteopathic Family Physician. 2011;3(2):58-65.

16. DeMeester TR, Bonavina L, Iascone C, et al. Chronic respiratory symptoms and occult gastroesophageal reflux. A prospective clinical study and results of surgical therapy. Annals of Surgery. 1990;211(3):337-345.

17. Gurski RR, Rosa ARP, Borba MA, et al. Extraesophageal manifestations of gastroesophageal reflux disease. J Bras Pneumo. 2006;32(2): $150-160$.

18. Knight RE, Wells JR, Parrish RS. Esophageal dysmotility as an important co-factor in extraesophageal manifestations of gastroesophageal reflux. The Laryngoscope. 2000;110(9):1462-1466.

19. Moraes-Filho JPP. The Brazilian Gerd Consensus Group et al. Diretrizes para o diagnóstico e tratamento da doença do refluxo gastroesofágico: um consenso baseado em evidências. Arq Gastroenterol. 2010;47(1):99-115.

20. Elsig J. Doença do refluxo gastroesofágico. Rev Bras Med. 199;56(12).

21. Chinzon D. Novos conceitos da fisiopatologia da doença do refluxo gastroesofágico. Simpósio: DRGE. Revista Gastroenterologia Contemporânea; 2002.

22. Ferreira SF. O tratamento osteopático do refluxo gastroesofágico [Monografia]. Belo Horizonte: Escola Brasileira de Osteopatia; 2007.

23. Epstein FH, Mittal RK, Balaban DH. The esophagogastric junction. New England Journal of Medicine. 1997;336(13):924-932.

24. Choung RS, Richard Locke G, Schleck CD, et al. Multiple functional gastrointestinal disorders linked to gastroesophageal reflux and somatization: A population-based study. Neurogastroenterology \& Motility. 2017;29(7):e13041

25. Bredenoord AJ, Weusten BL, Timmer R, et al. Intermittent spatial separation of diaphragm and lower esophageal sphincter favors acidic and weakly acidic reflux. Gastroenterology. 2006;130(2):334-340.

26. Bienfait M. Fáscias e pompages: estudo e tratamento do esqueleto fibroso. Summus Editorial: São Paulo, Brazil; 1999.

27. Barral JP, Mercier P. Médecine ostéopathique: manipulations viscérales. 1 st \& 2nd ed. Maloin: Paris; 1983. 